\section{A (anture}

\author{
o.
}

\section{THE DIAGNOSIS AND TREATMENT OF CANCER OF THE RECTUM.}

Delivered at the Cancer Hospital, Brompton, ON JANUARY 22ND, 1913.

BY

W. ERNEST MILES, F.R.C.S.,

SURGEON TO THE CANCER HOSPITAL AND TO THE GORDON HOSPITAL FOR RECTAL DISEASES, ETC.

The rectum is conveniently divisible into three parts

1. The anal canal-that portion embraced by the external and internal sphincters and by the horizontal fibres of the levatores ani.

2. The ampulla, consisting of a lower part below the peritoneal reflection and an upper part covered by peritoneum in front and at the sides only; and

3. The upper portion joining the terminal part of the pelvic colon at the level of the middle of the third piece of the sacrum about $4 \frac{1}{2}$ or 5 in. above the muco-cutaneous junction of the anus.

Abore this the bowel is pelvic colon. Anatomists formerly described as part of the rectum the portion of bowel extending from the left sacro-iliac synchondrosis to the middle of the third picce of the sacrum, but nowadays they relegate this portion to the pelvic colon, and we shall avoid a great deal of confusion if we follow them.

Cancer may occur in any of the three parts of the rectum. You see before you sixty specimens of the lower bowel removed for cancer, and an examination of them will convince you that in no single case is the lowermost border of the growth at a greater height than 5 in. from the anal margin. It is obvious, therefore, that a cancerous tumour of the rectum can always be reached by digital exploration, and that if the growth is beyond reach it is not in the rectum at all, but in the pelvic colon.

Now, the position of the growth has a consiclerable bearing on its appearance and on the symptomatology when the case first comes under observation. If it is situated in the upper portion it generally involves the whole circumference of the bowel and tends to produce invagination; if in the ampulla it usually encompasses from a half to four-fifths of the circumference, and in nearly all cases is found to have infiltrated the posterior wall; if it has arisen in the anal canal the anterior wall is generally the site of election, and from a third to a half of the circumference is involved.

\section{Symptons.}

It is of the utmost importance that the earliest symptoms indicative of the presence of a malignant tumour in the rectum should be known and recognized. The disease is insidious in its inception and early progress, and may exist for six months or longer before giving rise to symptoms which may induce the patient to seek advice. For this reason many cases do not come under observation until the disease is far advanced and beyond the limits of useful operation. About 25 per cent. of the cases under 60 years of age that I see are probably beyond operation. Let us see how the position of the growth affects the symptoms. If the neoplasm involves the anal margin, a situation where the mucous membrane is particularly well supplied with sensitive nerve terminals, pain is an early manifestation. If the growth is situated in the upper portion of the rectum, owing to the great tendency there to circular infiltration of the gut, a stenosis is produced and an attack of mechanical obstruction may ensue quite early. In both these cases the patients seel advice while the disease is still in an early phase of development. When the lesion occurs in the ampulla the case is different. Here the mucous membrane is much less sensitive, and the lumen of the bovel is so large that a considerable time must elapse before the entire circum. ference has been encompassed by the growth. Under these circumstances the pationt, until he begins to lose blood from the rectum, or notices a discharge, is not aware that there is anything of a serious nature amiss with him. There is a considerable latent period during which there are no objective symptoms at all, the growth being still in the pre-ulcerative stage. So soon as surface disintegration commences, bleeding from the rectum makes itself manifest, and this is generally the first objectire symptom that causes the patient to seek advice. The symptoms indicative of the presence of a cancerous growth in the ampulla of the rectum may be conveniently considered during the successive phases of its progress, as follows :

\section{(a) Symptoms Prior to the Disintegration of the} Sirface of the Growth.

From what I have already said it is obvious that the growth has existed for several months prior to the onset of the first objective symptom that impelled the patient to seek advice. But $I$ want to call your attention to a particular sign which is always suggestive of cancer of the rectum in this situation, and the two patients here to-clay are illustrative of its importance. Careful inquiry as to the habits of life during the year or two preceding the onset of objective symptoms will nearly always reveal the fact that a prolonged and well marked attack of constipation occurred several months beforehand. This attack of constipation is not of the ordinary kind which is speedily relieved by aperients, but is of the nature of a temporary functional inertia persisting for several days or weelis at a time and not yielding to treatment. Aperients appear to have little effect beyond producing small ineffective motions and the passage of flatus. After a period varying from three to six weeks, diarrlioea, slight at first but showing a tendency to become more marked, supervenes and persists. It is important, therefore, that a thorough examination of the rectum be made in every case in which diarrhoea supervenes upon a pro!onged attsck of constipation and persists in an other'wise healthy patient, since the possibility of carcinoma being the cause is very great and should not be lost sight of. The temporary inertia of the bowel is not associated with abdominal distension, indicating an absence of mechanical obstruction.

\section{(b) Symptcms During the Process of Surface} Disintegration.

The growth having become ulccrated, local symptoms of a more definite and objective character appear. The rectum becomes irritable and intolerant of the presence of faeces. Hence there is a desire to evacuate frequently, the bowels acting from twelve to twenty times during twenty-four hours. As a rule, the first and second evacuations consist of faeces, the remainder consisting almost entirely of mucus mixed with blood and pus. Bleeding, though occurring with each action of tho bowels, is seldom copious, but is more marked in cases of papilliferous cancer than in the infiltrating adenocarcinoma. If the bleeding is frce, the blood generally comes from coexistent internal piles. The appearance of an increased quantity of mucus in the stools is characteristic of ulceration of the growth taking place. This mucus is peculiarly offensive in odour. Local pain in the rectum from the contact of the faeces witli the riwerated surface is usually present, though not severe, as lung as the growth does not extend into the anal canal. When the anal canal becomes involved, the pain is aciic at eac! movement of the bowels, and persists for some time ait terwards. During this stage of the disease the patient bogins to lose flesh in a decided manner. The loss of rivint generally begins to show itself in from six to twelve months after the initial attack of constipation, and becomes progressive. If bleeding is free, and especially if suppuration is profuse, emaciation sets in, and is frequently rapid.

(c) Symptoms when the Growth has Infiltrated tiie Perirectal Tissues and Peiforation of tho Rectal Wall has Talien Place.

When the disease has reached this stage the symptoms are pronounced, and usually indicate the implication of neighbouring viscora. They consist of haemorrhage, which is often frec; pus in considerable quantity on account of pelvi-rectal suppuration and the development of ischio-rectal fistulae; deep-seated pain in tine pelvis, over the sacrum, and extending down the thighs from 
implication of the sacral plexus by extramural spread of the disease; and the supervention of general cachexia from chronic septic absorption.

\section{(d) Symptoms when almost Complete Occlusion of the} Lumen has Supervened.

This stage is generally reached in eighteen months or two years after the onset of the earliest symptoms, and the disease is then too far advanced for removal. The attendant symptoms are: (1) Obstinate constipation alternating with diarrhoea ; (2) local pain and intermittent attacks of abdominal pain ; (3) intermittent haemorrhage (4) increasing abdominal distension ; (5) rapid emaciation and finally (6) an attack of absolute obstruction.

Examination of a Cancerous Tumour of the Rectum.

A thorough exploration of the whole of the rectum in a systematic manner is the most reliable way of detecting the presence of malignant disease. The finger should be introduced to its full extent, so that the highest possible point can be reached. With an ordinary length of finger the promontory of the sacrum can nearly always be felt. The finger should then be swept round the entire circumference and gradually withdrawn as each encirciing move. ment is made. In this way even a small nodule in the rectal wall can scarcely be missed. If a tumour be felt the following points should be noticed. Is the growth sessile or pedunculated? Is the surface smooth, lobulated, or excoriated? How much of the circumference is impli cated by the growth; is the lumen of the bowel at the site of the growth stenosed? if so; can the finger be introduced through the stenosis? Is the growth movable or fixed to the muscular coat? if so, is the diseased part of the bowel movable or fixed? Finally, does the growth extend upwards beyond the reach of the finger?

Additional information as to mobility and possible extramural permeation may be obtained by bimanual examination, under an anaesthetic if necessary. The sigmoidoscope should always be used in order to verify the findings of the digital examination. You will have the opportunity of examining the condition in these two cases by the sigmoidoscope.

\section{Differential Diagnosis.}

From the clinical point of view the conditions which are most likely to be mistaken for carcinoma are polypus, villous.papilloma, benign stricture, invagination of the rectum, gummatous deposits, and tubsculous ulceration. Polypi are very rare in adults. They are soft, pedunculated, free from induration, and seldom of a large size. Villous papilloma is fairly common. It is pedunculated and may reach a large size. Its surface is soft and irregular, and as it secretes a large quantity of watery fluid it produces frequent evacuations of the bowels, but no incluration exists anywhere. In benign stricture the margin is firm and regular ; it does not bleed, and it is freely movable and generally accompanied by a purulent discliarge. Invagination of the rectum may, when advanced, simulate carcinoma, but it is distinguishable from cancer by its even contour, the regular outline of its lumen, and the absence of induration. Gummata of the rectum are rare, and they may be distinguished from cancer by their smooth, round, elastic feeling, by the history of antecedent syphilis, and by the result of a Wassermann reaction. Tuberculous ulceration is not very common. It is difficult of diagnosis owing to the swelling produced and the chronic inflammatory thickening accompanying it, as you will see from the specimen shown; but in tubercle the ulceration is generally super ficial, and the edges of the ulcer are not everted. 'Evidence of tuberculosis in other parts is often found.

The Evolution of the Growth.

An early adeno-carcinoma of the rectum forms a sessile, rounded, or oblong tamour, involving the mucous and submucous coats of the bowel. The growth increases in size in all directions, though apparently more rapidly in a transverse than in an upward or downward direction. Though at first freely movable on the subjacent muscular coat, it sooner or later becomes adherent to it. This adherence denotes that infiltration has commenced, and giadually the whole tumour becomes firmly fixed to the wall of the bowel. It is impossible to determine how long infiltration of the muscular coat occurs after the primary appearance of the growth as a definite tumour, as cases vary in the rapidity of their evolution, but from a calculation based on the time of onset of the first symptoms I should say that six months is a rough average. As the growth increases in size the oldest part of the surface, probably owing to malnutrition, disintegrates and a definite ulcer appears-superficial at first, but gradually becoming deeper. The ulcer exhibits the well-known malignant characteristics of an irregular indurated margin, an uneven, excavated surface, and an indurated base. The lateral extension of the growth is not rapid, and when one-half of the bowel has been encroached upon tho disease has probably been in existence for about a year, when three-fourths or five-sixths have been involved tho growth is from eighteen months to two years old. These are rough averages. As the growth encompasses more and more of the circumference the wall becomes corre spondingly rigid, and marked narrowing of the lumen results. Concurrently with the increase in size the spread of the disease is taking place partly by infiltration and partly by permeation of the lymphatics. Spread occurs both intramurally and extramurally. . Intramurally the cells grow along the submucous lymphaties only to a very slight extent longitudinally in the mafority of cases. They tend more to permeate by radial intramuscular channels to a deeper lymphatic plexus, where the area of spread may be of considerable extent, and from this they are conveyed by collecting channels running extramurally to the lymph glands. The clinical fact that recurrence may take place in the cut end of the bowel at a distance of several inches from the site of original growth strongly supports the view that cancee cells may permeate the intramural lymphatics for a con'. siderable distance. It is impossible to state how soon after a cancerous tumour has developed extramural spread occurs. It is quite. wrong to suppose that it takes placo very late in the course of the disease. I have seen several small and freely movable growths, clinically early, which had given rise to widespread lymphatic involvement and to deposits of cancer in the pelvic mesocolon and pelvic peritoneum at a distance of several inches from the site of primary growth. Visible spread like this can only be recognized when the abdomen is opened and cannot possibly be detected by the ordinary methods of rectal examination. The invisible spread is much more subtle. From clinical observations of post-operative recurrences, I am quite convinced that cancer cells, even in cornparatively small and early growths, invade the lymphatic channels to a distance far beyond the limits of the visible spread, and consequently all the tissues contained in tho lymphatic areas leading from the primary growth to tho lymph glands must be regarded as invaded territory. I divide these areas into three-the zones of downward, lateral, and upward spread. There is a free intercommunication between the lymphatics of the rectal wall and those contained in the ischio. rectal fat, perianal skin, and the external sphincter. Involvement of this area does occur even when tho primary growth is situated in the upper part of the rectum. The lateral zone compríses the levatores ani, retrorectal lymph glands, internal iliac glands, the prostate, the base of the bladder, and, in the female, the cervix uteri, and the base of the broad ligament with Poirier's gland. Situated between the upper surface of the levators and the pelvie diaphragmatic fascia there is an extensive lymphatic plexus which freely communicates with the intramural Iymphatics. In several cases I have observed small plaques of growth located either in the substance of the levators or upon their-upper surface close to the rectal wall, and, in one instance, in the substance of the muscle close to the origin of the muscle from the pelvis. The levator ani muscle is therefore exceedingiy vulnerable to the spread of rectal cancer, and should in all instances be freely removed. The zone of upward spread is the most important of the three. The structires in this lymphatic area are-the peritoneum of the floor of the pelvis, the whole length of the pelvic mesocolon, the paracolic lymph glands, and the glands grouped at tlie bifurcation of the left common iliac artery. Spread occurs into these very rapidly.

I have gone very briefly into the pathology of the spread in order to show you that any operation on cancer 
of the rectum that is useful at all must remove certain areas of highly dangerous tissue. The facts of surgical pathology alone are sufficient to damn all such restricted operative procedures as perineal excision and resection with end-to-end anastomosis. I cannot speak of the end results of perineal operation in the hands of others. I only know that I gave them far too long a trial, extending their scope as far as possible, limiting my selection of cases more than I do now, and faithfully following my results. I did 58 such operations; I had 55 recurrences; and $I$ am convinced.

\section{Treatment.}

The failures of restricted operations and the observations clinically on the areas of vecurrence led me to devise the radical abdomino-perineal operation. I shall not now describe my operation, but you will have the opportunity to-morrow of seeing one of these cases operated upon by the method; the other will be operated upon on Thursday, January 30th. Briefly, the operation consists in removing nearly the whole of the pelvic color, the whole of the mesocolon, the whole of the levatores ani, and the whole of the rectum and anus and ischio-rectal tissues, and making a permanent inguinal colostomy. You will see the results in those patients who have been good enough to return to us to-day for examination after three and more years since the operation, and you will find that they have practically complete sphincteric control of the abdominal anus, and that this artificial anus is neither uncleanly nor unsightly, nor is it a source of discomfort. The operation is a severe one. I do not think that it should be performed on those over 60 years of age; of 10 such cases all died. With regard to the remainder, of whom there were 36,8 died from the effects of the operation, 4 have had recurrence, 2 died of intercurrent disease, while 22 are to-day alive and well after periods varying from six months to six years.

\section{fttemaramda:}

\section{MEDICAL, SURGICAL, OBSTETRICAL.}

\section{THE TREATMENT OF OBSTINATE SCIATICA BY} PHENAZONUM INJECTIONS.

The treatment of obstinate sciatica is attended with so many difficulties that success by Tubache's method ' may be of interest.

A. V., aged 66, of robust constitution, weight 15 stone, came under my care on August 30th, 1912. He had had a sharp attack of sciatica in 1886, and was quickly cured by the baths of Hammam R'Irha, Algiers; again, in 1905, he was apparently cured of another attack by visiting the same baths. An attack in September, 1911, was greatly relieved by three weeks of Harrogate treatment, baths, massage, electricity, etc., and in June, 1912, after a sharp attack of lumbago, a more severe trouble arose from a return of the sciatica. Three weeks at Droitwich; baths, massage, and Aix douche made the patient's condition steadily worse. He returned home and took to his bed on September 3rd. The daily application of an electric light bath was tried, and blisters along the course of the sciatica nerve, salicylates, potassium iodide, and other remedies, but he continued to experience the most acute pain on the slightest movement. He could only lie on his left side, the sciatica affecting his right leg from thigh to foot.

On September 21st I commenced the deep hypodermic injections of the following: Phenazonum, 3 ijss; cocain.

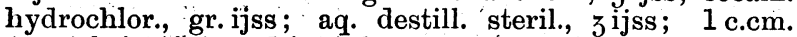
(in xv) being injected into the upper part of the thigh over the nerve. The injection was repeated at different places along the course of the nerve on September 23rd, 25th, 27th, and October 3rd, 7th, 9th, 13th, 17th. They caused no pain at the time, but invariably about 6 hours after a great deal was experienced, which lasted some hours, and sometimes necessitated an injection of morphine. "There was no great relief from the treatment until October 12th, but the nearer the injection got to the nerve the greater

1 Practitioner, July, 1912. the relief seemed to be. For instance, the injection over the external popliteal behind the head of the fibula gave great relief, and another injection, on October 13th, on the dorsum of the foot completely removed the pain after four hours, and it has not returned.

After October 12th the patient rapidly improved; the pain ceased and movement became easy. About this time some anxiety was felt because of some slight cardiac trouble, causing a slow and intermittent pulse; but a mixture of strychnine and digitalis put this right again. Since October 28th the patient has gradually resumed his usual habits, and experiences only a considerable stiffness in his right leg. The power of walking is gradually improving.

High Wycombe, Lewis W. Reyxolds, M.R.C.S.Eng.

\section{RUPTURE OF THE PLEURA WITHOUT FRACTURE OF RIBS CAUSED BY A BUFFALO.}

W. 'R., a German hunter aged 27 ; was attacked by a buffalo on October 7th, 1912, near Kasîsi Camp, on the Anglo-Belgian frontier, about 40 miles from Fort Portal, Toro, in the Uganda Protectorate.

The buffalo first attacked a native porter, goring him in the abdomen from one side to the other as it tossect him. The man died on the spot. It next turned its attention to W. R., threw him on his back, and tried to crush him by pressing his chest with its head. With great presence of mind W. R. then pushed two fingers of each hand into the animal's eyes, which made it start back suddenly. Bcfore he could get hold of his rifle (which lay by his side) the buffalo made a second rush at him and tried to crush him as before, the hunter trying to relieve the pressure by seizing both the animal's horns. In the meantime one of the other porters succeeded in killing the buffalo after three shots.

In the struggle the following injuries were sustained:

1. General bruising of the whole body and limbs.

2. A lacerated wound of the neck on the right side, and a double wound of the middle of the right arm, caused by penetration with the horn, and another lower down.

3. The principal injury, however, was rupture of the pleura between the fourth and fifth rib just outside the nipple line for 4 to 5 in.

The patient was first secn by me on October 11th, four days later. Ho was very anacmic, and there was a well marked mitral bruit. At each expiration the lung protruded from the aperture above described to the size of a large walnut. There was extensive emphysema of the chest wall up to the sixth rib in front and to the fourth in the axillary line. No pleuritic rub could be heard, being probably masked by the crepitations. The base of the lung was clear. The temperature was $101^{\circ} \mathrm{F}$., the pulse 100 , and the respirations 32 .

A pleuritic rub was heard reaching to the base of the left lung on October 14th. The temperature was $98.6^{\circ}$ in the morning, and $102.4^{\circ}$ at $8 \mathrm{p} . \mathrm{m}$.

The patient made a rapid recovery, and on October 18 th the temperature was $98.2^{\circ}$, the pulse 84 , and the respirations 26. 'The treatment was then stopped at the patient's request, but there was still dyspnoea aud pain on November $2 \mathrm{nd}$.

\section{Note by Dr. Cropper, late of the C.M.S. Hospital,} Toro.

I saw this patient on November 2nd and three following days. He was very anaemic, and I diagnosed malaria; this was confirmed by the microscope, which showed well marked benign tertian rings. Quinine in doses of gr. $x \nabla$ quickly put an end to the fever. The wounds were nearly healed. Pain in the left chest was diminishing, but there was still dullness at the left base, probably due to effused blood still unabsorbed. The rent in the pleura was closing, bit on forcible expiration there was still a small protrusion of the lung nearer to the shoulder-joint than the nipple, and apparently more external than just after the injury. This could be controlled by a well fitted pad strapped on. S. R. Bhagwât, L.R.C.S.E., Government Surgeon, Fort Portal, Uganda. 